\title{
DETERMINACIÓN DE ZONAS PROPENSAS AL VIRUS DE LA MANCHA BLANCA EN PISCINAS CAMARONERAS DE LA ISLA PUNÁ MEDIANTE EL CÁLCULO DE TEMPERATURA SUPERFICIAL CON ALGORITMO SPLIT-WINDOW
}

\author{
DETERMINATION OF PROPENSIVE ZONES TO THE WHITE SPOT VIRUS IN \\ SHRIMP PONDS OF PUNA ISLAND THROUGH THE SURFACE TEMPERATURE \\ CALCULATION WITH SPLIT-WINDOW ALGORITHM
}

\author{
KAROL ARELLANO ${ }^{1}$, PABLO PADILLA ${ }^{1}$, IÑIGO MOLINA ${ }^{2}$ \\ ${ }^{1}$ CARRERA DE INGENIERÍA GEOGRÁFICA Y DEL MEDIO AMBIENTE, UNIVERSIDAD DE LAS \\ FUERZAS ARMADAS - ESPE. Av. Gral. Rumiñahui s/n. Sangolquí - Ecuador, kdarellano@espe.edu.ec; \\ phpadilla2@espe.edu.ec. \\ 2 ETSI EN TOPOGRAFÍA, GEODESIA Y CARTOGRAFÍA. CAMPUS SUR, UNIVERSIDAD \\ POLITÉCNICA DE MADRID, Ctra. de Valencia, km.7, 28031 Madrid, España, inigo.molina@upm.es.
}

Recibido: 11 de abril de 2019 / Aceptado: 12 de junio de 2019

\section{RESUMEN}

La temperatura superficial es un indicador del equilibrio energético de la superficie terrestre u oceánica, sus principales aplicaciones se centran en estudios ambientales, como el clima urbano, monitoreo de la vegetación, hidrología, entre otros. Debido a su gran importancia para el estudio de calidad del agua, requiere de mediciones, las cuales se pueden obtener mediante la aplicación de distintos algoritmos matemáticos en teledetección. El objetivo de este estudio fue identificar zonas propensas a la aparición del virus del síndrome de la mancha blanca (WSSV) en piscinas camaroneras de la Isla Puná para los años 2016 y 2017 mediante el cálculo de la temperatura superficial. En esta isla la especie conocida como Litopenaeus vannamei (camarón blanco del Pacífico) es la de mayor producción en su territorio, sin embargo, cuando la temperatura de las piscinas destinadas a su cultivo alcanzan valores inferiores o iguales a los $27{ }^{\circ} \mathrm{C}$, se favorece a la aparición de brotes del virus de la mancha blanca. Para el cálculo de temperatura superficial se utilizó el algoritmo split-window propuesto por Sobrino et al. (1996) y datos combinados de los sensores Landsat 8 OLI/TIRS y ASTER. Como resultados se obtuvo que para el año 2016, un 0,13\% (16.20 ha) del área total (12 569,76 ha) de piscinas camaroneras presentaron riesgo de brote del virus de la mancha blanca, mientras un 12,91\% (1 644,48 ha) del área total (12 736,80 ha) de piscinas identificadas fueron identificadas en el año 2017, que es un porcentaje mucho más representativo en comparación con el registrado en el año 2016, lo cual refleja la falta de un mejor control en el proceso de producción camaronera. Finalmente este trabajo presenta un aporte importante a la tecnología y métodos de cuidado para disminuir el riesgo de que la especie Litopenaeus vannamei contraiga el virus de la mancha blanca.

Palabras clave: radiancia, emisividad, temperatura superficial, split-window, teledetección 


\begin{abstract}
The surface temperature is an indicator of the energy balance of the land or ocean surface, its main applications are focused on environmental studies, such as urban climate, vegetation monitoring, hydrology, among others. Because of its great importance for the study of water quality, it requires measurements, which can be obtained through the application of different mathematical algorithms in remote sensing. The objective of this study was to identify susceptible areas to the appearance of the white spot syndrome virus (WSSV) in shrimp ponds of Puná Island for the years 2016 and 2017 through the surface temperature calculation. In this island the species known as Litopenaeus vannamei (Pacific white shrimp) is the one with the highest production in its territory, however, when the temperature of the ponds destined for its cultivation reach values lower or equal to $27^{\circ} \mathrm{C}$, it is favored to the appearance of outbreaks of the white spot virus. For the calculation of surface temperature, it was used the split-window algorithm proposed by Sobrino et al. (1996) and combined data from Landsat 8 OLI/TIRS and ASTER sensors. As results were obtained that for the year 2016, a $0.13 \%$ (16.20 ha) of the total area (12 569.76 ha) of shrimp ponds presented risk of outbreak of the white spot virus, while a $12.91 \%$ (1 644.48 ha) of the total area $(12,736.80 \mathrm{ha})$ of ponds were identified in the year 2017, which is a much more representative percentage compared to the one registered in 2016, which reflects the lack of a better control in the shrimp production process. Finally, this work presents an important contribution to technology and methods of care to reduce the risk of the species Litopenaeus vannamei contracting the white spot virus.
\end{abstract}

Keywords: radiance, emissivity, surface temperature, split-window, remote sensing

\title{
1 INTRODUCCIÓN
}

La teledetección es una técnica que tiene por objeto la adquisición de información sobre fenómenos que se producen en la superficie de la Tierra mediante la captura, tratamiento y análisis de imágenes digitales tomadas desde satélites artificiales (Aguilar et al., 2014). En las últimas décadas, se han puesto en órbita diversos proyectos de observación terrestre que permiten medir en muchos rangos de longitudes de onda y monitorear cualquier parte del planeta (Chuvieco, 1992). Los satélites Landsat y ASTER han sido unos de los más destacados, específicamente Landsat 8 y ASTER GED, que detectan datos infrarrojos térmicos y de emisividad, respectivamente, los cuales son imprescindibles para medir la temperatura en la superficie de la Tierra (NASA, 2018).

Según Sarricolea y Vide (2014) el cálculo de la temperatura superficial es importante en estudios de climatología tanto en la superficie terrestre como oceánica, y se obtiene a partir de la relación entre la energía emitida por la superficie y la recibida en el sensor, sin embargo, la radiancia que llega al sensor desde el objeto de estudio puede presentar distorsiones en sus valores por el efecto intrusivo de la atmósfera, lo cual se corrige mediante algoritmos matemáticos (Sarría, 2018). Uno de estos algoritmos matemáticos es el llamado split-window, que se basa en la diferencia de absorción entre dos bandas TIR para la corrección de efectos atmosféricos (Dražen, 2017). Fue inicialmente aplicado para la obtención de la temperatura de la superficie del mar, la cual posee una emisividad conocida y homogénea, y que según Galve (2014) provoca que dicho algoritmo funcione muy bien en este tipo de superficie, por lo que se podría considerar como una técnica apropiada y alternativa a las mediciones in-situ que comúnmente se realizan para el control de temperatura en piscinas camaroneras.

La temperatura del agua en piscinas destinadas al cultivo de camarón comprende uno de los factores más importantes para el crecimiento, muda y sobrevivencia de este crustáceo (Esparza et al., 2012). Cuéllar-Anjel (2013), sugiere que temperaturas inferiores a los $27^{\circ} \mathrm{C}$ pueden actuar 
como un factor estresante y que favorece en la aparición de brotes de enfermedades virales de camarón, como el virus del síndrome de la mancha blanca (WSSV), que según Briggs et al., (2005) históricamente fue una de las principales amenaza que enfrentó la industria del cultivo de camarón a nivel mundial.

En Ecuador, el sector camaronero provee uno de los productos de mayor importancia en la exportación y, por consiguiente, un rubro significante en el ingreso de divisas que inciden en la economía interna del país (Santana, 2015). Entre los años 1999 y 2000, el virus de la mancha blanca redujo la producción camaronera del país en un 30\%, una crisis que a partir del año 2006 logró estabilizarse, debido a los cambios tecnológicos y nuevos métodos de cuidado para el camarón, que han logrado mejorar su calidad de producción y han disminuido el riesgo de que este crustáceo contraiga el virus (Vélez, 2015).

El propósito de esta investigación fue identificar zonas vulnerables a la aparición del virus del síndrome de la mancha blanca (WSSV) a partir del cálculo de la temperatura superficial en piscinas camaroneras de la Isla Puná mediante un algoritmo bicanal o split window basado en el uso de las bandas térmicas del sensor Landsat 8 OLI-TIRS y datos ASTER-GED de emisividad.

\section{ZONA DE ESTUDIO}

El área de trabajo que se propuso a evaluar, fueron las piscinas camaroneras presentes en la Isla Puná, ubicada en la boca del golfo de Guayaquil, provincia del Guayas, Ecuador (Figura 1), donde según Armas e Izquierdo (2010) se encuentran asentadas gran parte de las empresas camaroneras del país, las mismas que en su mayoría optan por el cultivo del Camarón Blanco del Pacifico (Litopenaeus vannamei); dando lugar a que esta especie sea la de mayor producción en la zona. Estudios sugieren que temperaturas iguales o inferiores a $27{ }^{\circ} \mathrm{C}$, incrementan el riesgo de brotes de mancha blanca en la especie Litopenaeus vannamei, mientras que temperaturas iguales o superiores a $28{ }^{\circ} \mathrm{C}$ podrían ser adecuadas para el buen funcionamiento de sus mecanismos de defensa (Blake, 2004).

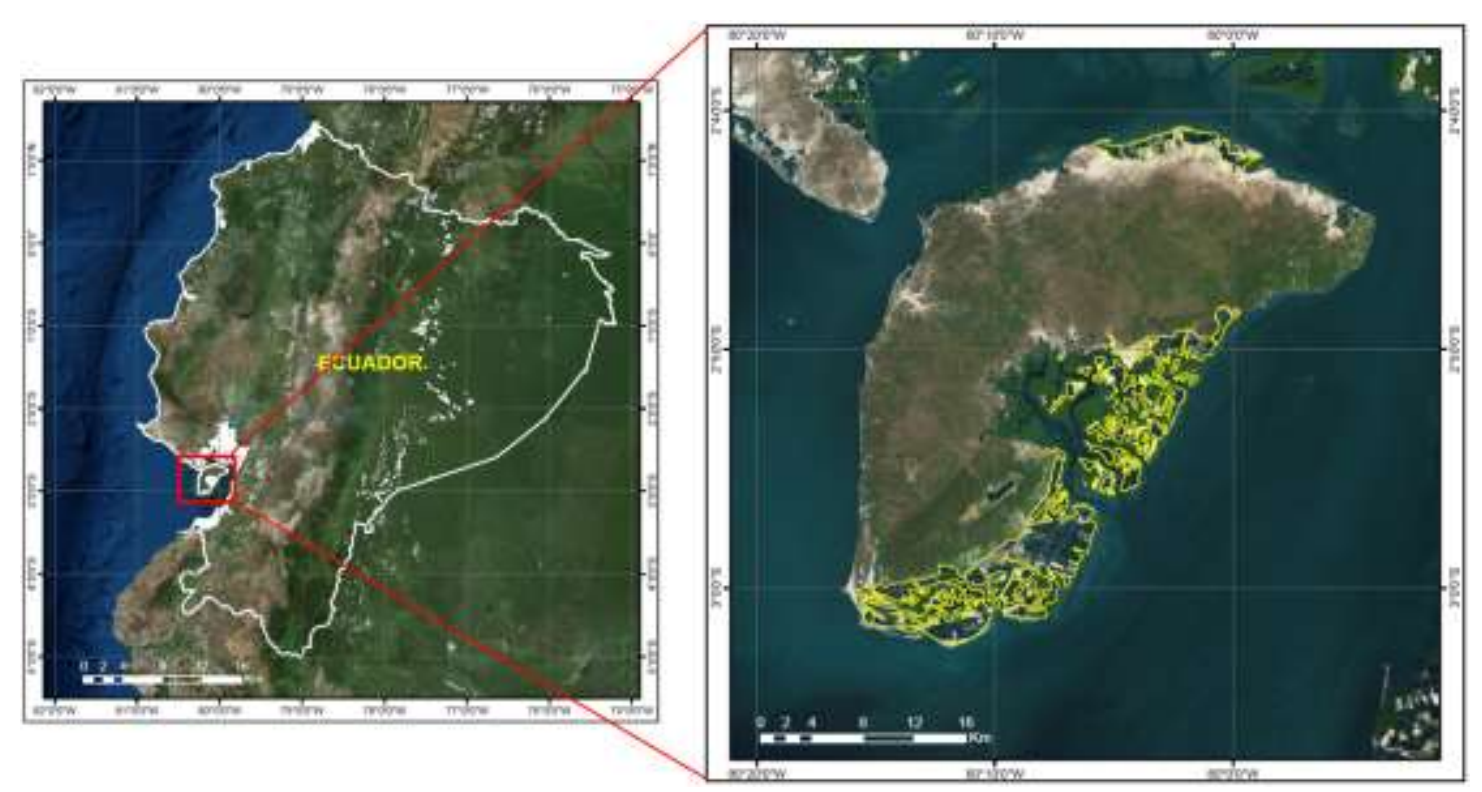

Figura 1. Ubicación de piscinas camaroneras en la Isla Puná 


\section{METODOLOGÍA}

La metodología fue estructurada en cuatro secciones principales, de acuerdo al manejo y cálculo de los datos y variables de interés. En primer lugar se describe los datos e información descargada, luego el procedimiento para la delimitación de las piscinas camaroneras, posteriormente el manejo y obtención de los datos de emisividad global ASTER-GED, y finalmente se expone el algoritmo split-window utilizado para el cálculo de la temperatura superficial en la zona de estudio.

\subsection{ADQUISICIÓN DE DATOS E INFORMACIÓN}

Para este estudio se utilizaron dos imágenes Landsat 8 OLI/TIRS capturadas el 19 de mayo de 2016 y el 13 de octubre de 2017, que fueron descargadas y obtenidas de forma gratuita desde portal de la NASA, de las cuales, en específico se manejaron las bandas térmicas 10 (TIRS-1) y 11 (TIRS-2) que poseen una resolución espacial de $100 \mathrm{~m}$, en específico estas bandas al ser descargadas ya vienen resampleadas a $30 \mathrm{~m}$. Además se seleccionaron cuatro imágenes de la misión ASTER GED (Advanced Spaceborne Thermal Emission and Reflection Radiometer Global Emissivity Database) adquiridas entre 2000-2008, que cubren la zona de estudio, obteniendo datos de emisividad global al manejar sus bandas 13 (TIR-4) y 14 (TIR-5) con una resolución espacial de 100 metros. Las imágenes ASTER-GED fueron georreferenciadas al sistema WGS84 con coordenadas UTM (Zona 17 Sur) en función de sus metadatos, mientras que las imágenes Landsat 8 OLI/TIRS ya se encontraban georreferenciadas.

\subsection{DELIMITACIÓN DE LAS PISCINAS CAMARONERAS}

Para la delimitación de las piscinas camaroneras en la Isla Puná, se realizó una combinación NIR, RED, GREEN con las bandas 5, 4, 3 de las imágenes Landsat 8 OLI/TIRS de los años 2016 y 2017, la cual es útil para identificar límites entre el suelo y agua, permitiendo así distinguir las zonas de manglar de las piscinas camaroneras, a fin de obtener polígonos únicamente de la zona de interés.
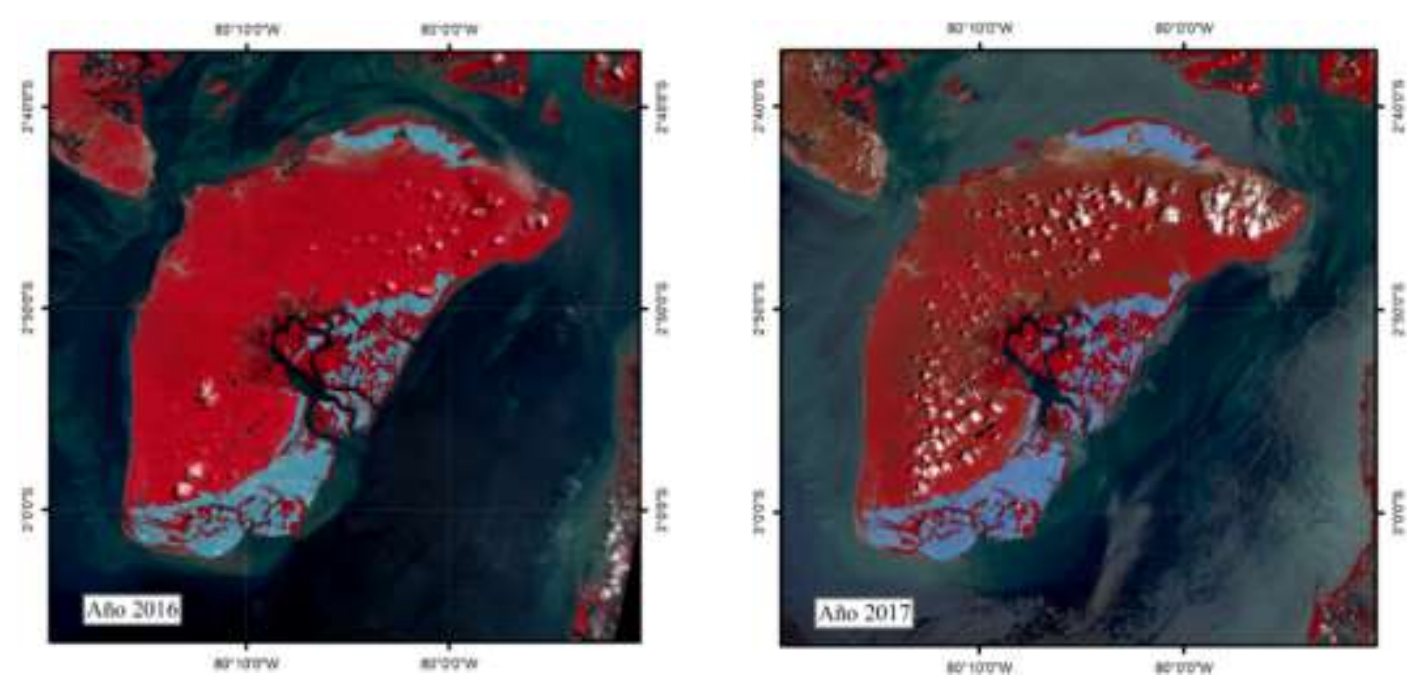

Figura 2. Delimitación de piscinas camaroneras en la isla Puná a) año 2016 y b) año 2017 


\subsection{MANEJO DE DATOS DE EMISIVIDAD}

Para los datos de emisividad, se procedió a utilizar las bandas TIR-4 (10.25-10.95 um) y TIR-5 (10.95-11.65 um) del sensor ASTER GED, que como se aprecia en la Tabla 1, presentan longitudes de onda con rangos similares a las bandas TIRS-1 (10.6-11.19 um) y TIRS-2 (11.5$12.51 \mathrm{um})$ de Landsat $8 \mathrm{OLI} / \mathrm{TIRS}$, razón por la cual se pueden considerar como datos de emisividad propios de cada banda térmica (TIRS-1 y TIRS-2), y de esta forma sustituir sus emisividades requeridas en el método split-window.

Tabla 1. Correspondencia entre bandas térmicas Landsat 8 y datos de emisividad ASTER-GED

\begin{tabular}{|l|c|c|}
\cline { 2 - 3 } \multicolumn{1}{c|}{} & Landsat 8 & ASTER-GED \\
\hline Banda & TIRS-1 (Banda 10) & TIR-4 (Banda 13) \\
\hline Bangitud de onda & $10.6-11.19$ um & $10.25-10.95$ um \\
\hline Longitud de onda & TIRS-2 (Banda 11) & TIR-5 (Banda 14) \\
\hline
\end{tabular}

Fuente: (NASA, 2014)

\subsection{CÁLCULO DE TEMPERATURA SUPERFICIAL}

Para este estudio se aplicó el método split-window o también conocido como bicanal, el cual se basa en la absorción diferencial en dos bandas espectrales adyacentes, ubicadas en la ventana atmosférica comprendida entre $10.5 \mu \mathrm{m}$ y $12.5 \mu \mathrm{m}$ para corregir los efectos atmosféricos (Sobrino et al., 2000). Según Becker y Li (1990), el primer algoritmo SW fue propuesto inicialmente por McMillin en 1975 en un estudio para la estimación de la temperatura superficial del mar, y posteriormente modificado por otros autores, uno de los más conocidos es el algoritmo propuesto por Sobrino et al. (1996), el cual aún sigue siendo aplicado en estudios actuales (Jiménez-Muñoz \& Sobrino, 2008) (Li \& Geng-Ming, 2018).

\subsubsection{Algoritmo split-window propuesto por Sobrino}

El algoritmo split-window propuesto por Sobrino et al. (1996) permite calcular la temperatura superficial mediante la ecuación 1, sin embargo cabe mencionar que en esta ecuación, los datos de emisividad comúnmente obtenidos de las bandas propias de Landsat 8 OLI-TIRS, fueron sustituidos por datos específicos de emisividad global captados por el sensor ASTER, es decir, se realizó una combinación de datos de ambos sensores como se describe a continuación:

$$
T_{s}=T_{i}+C_{1}\left(T_{i}-T_{j}\right)+C_{2}\left(T_{i}-T_{j}\right)^{2}+C_{0}+\left(C_{3}+C_{4} W\right)(1-\varepsilon)+\left(C_{5}+C_{6} W\right) \Delta \varepsilon
$$

Donde

$\boldsymbol{T}_{\boldsymbol{s}}$ : Representa la temperatura de superficie

$\boldsymbol{T}_{\boldsymbol{i}} \mathbf{y} \boldsymbol{T}_{\boldsymbol{j}}$ : Representan la temperatura de brillo en las bandas 10 y 11 de Landsat 8 respectivamente $\boldsymbol{C}_{\mathbf{0}}-\boldsymbol{C}_{\mathbf{6}}$ : Son los valores de los coeficientes del algoritmo obtenidos con las simulaciones del MODTRAN y se especifican en Jiménez-Muñoz et al., (2014).

$\boldsymbol{W}$ : Es el contenido en vapor de agua de la atmósfera en la dirección de observación del sensor como lo especifica Shahid (2014)

$\boldsymbol{\varepsilon}$ : Representa la emisividad promedio de las bandas 13 y 14 de ASTER GED.

$\Delta \boldsymbol{\varepsilon}$ : La diferencia de emisividad de las bandas 13 y 14 de ASTER GED. 


\section{RESULTADOS Y DISCUSIÓN}

Los resultados de temperatura superficial obtenidos por el método split-window se visualizan y resumen de manera general en los mapas de las Figuras 3 y 4, y los histogramas de las Figuras 5 y 6 para el año 2016 y 2017 respectivamente. En ambos años se puede apreciar que el rango de temperatura entre $\operatorname{los} 27^{\circ} \mathrm{C}-33^{\circ} \mathrm{C}$ prevalece en las piscinas camaroneras, lo que indicaría en que los camarones de la mayoría de piscinas tienen un riesgo bajo de contraer el virus.

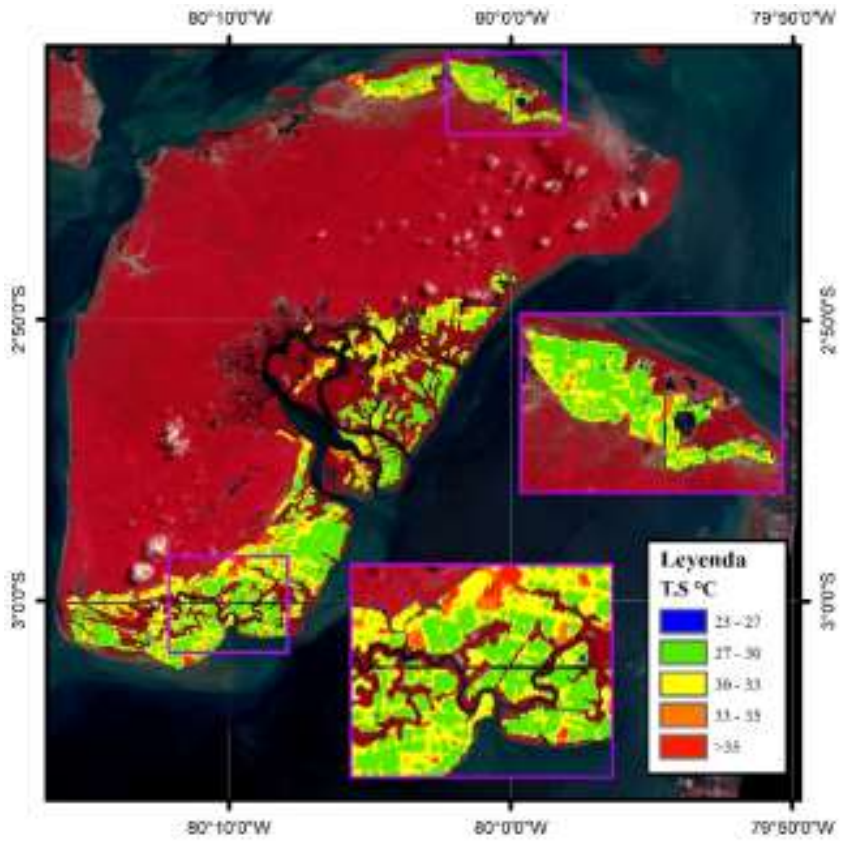

Figura 3. Mapa de temperaturas obtenidas para el año 2016

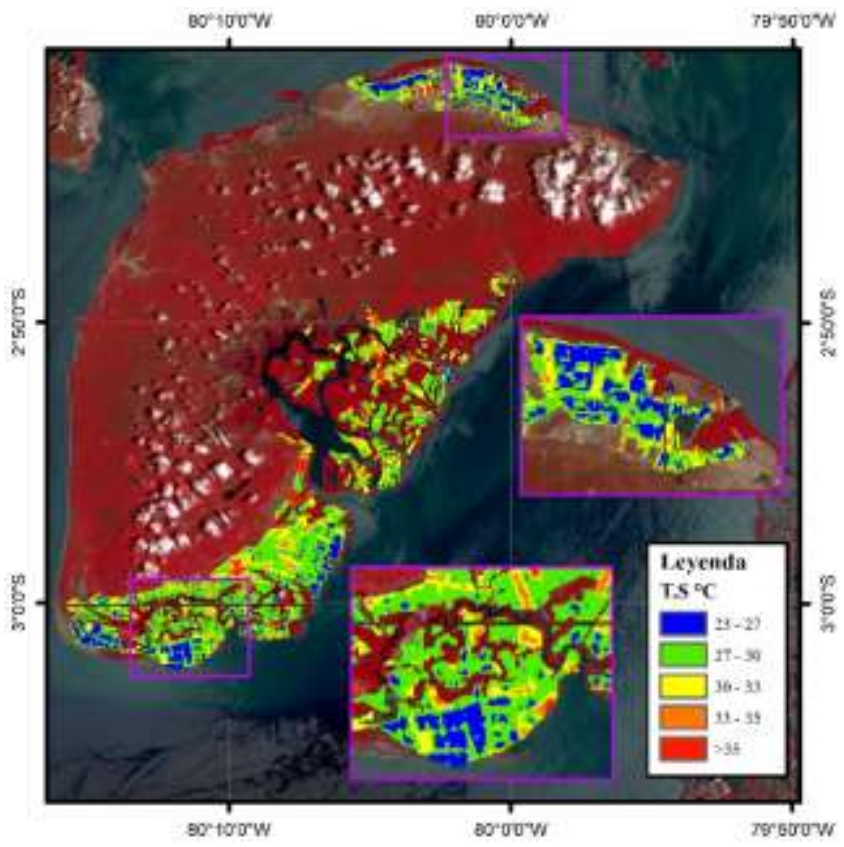

Figura 4. Mapa de temperaturas obtenidas para el año 2017 


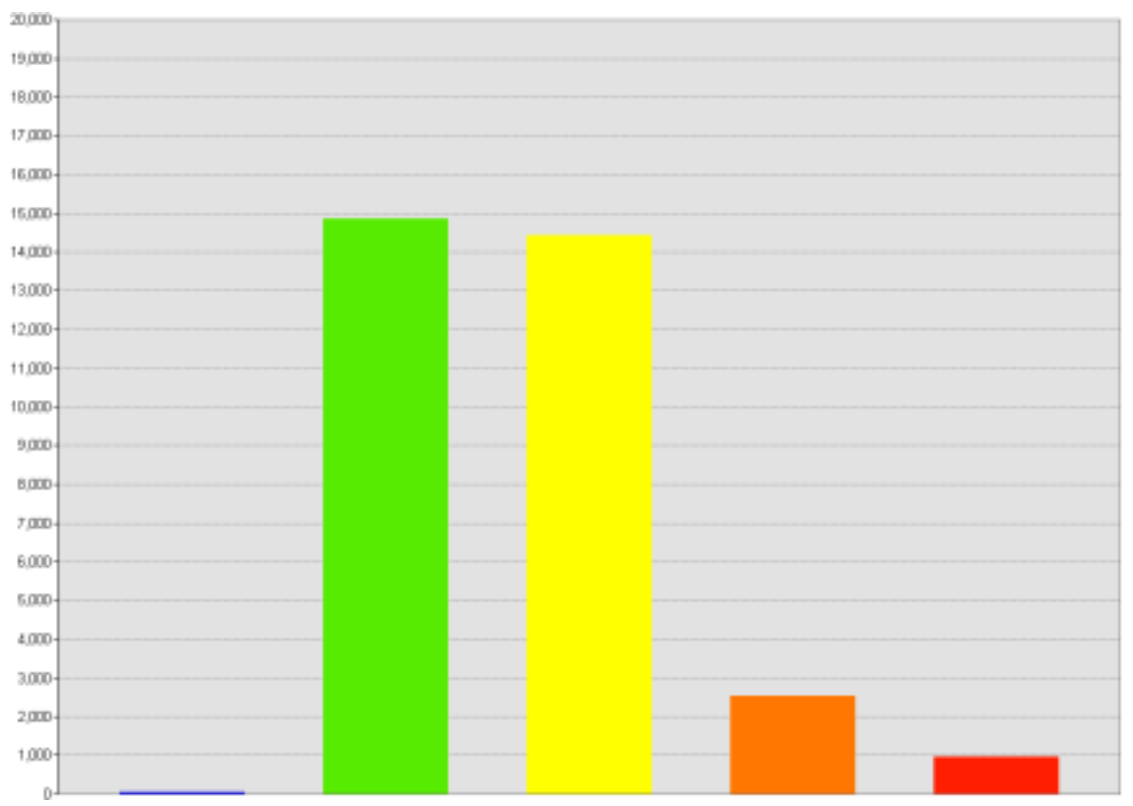

Figura 5. Histograma de temperaturas obtenidas en el año 2016

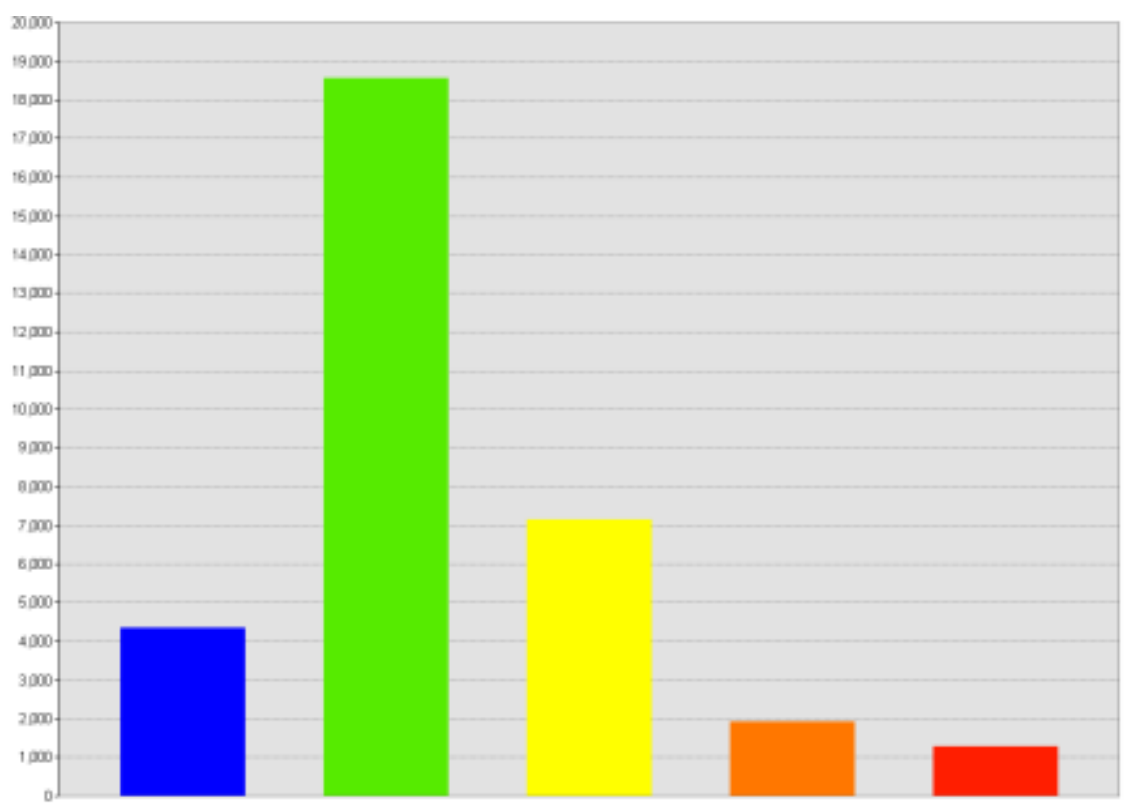

Figura 6. Histograma de temperaturas obtenidas en el año 2017

A continuación, en la Tabla 2, se muestra la superficie correspondiente de las piscinas camaroneras que presentaron temperaturas iguales o inferiores a los $27^{\circ} \mathrm{C}$, y que según Blake (2004) incrementan el riesgo de brotes de mancha blanca en la especie Litopenaeus vannamei, lo que las convierte hasta cierto punto en zonas vulnerables para la aparición de este virus. 
Tabla 2. Cuantificación de áreas con riesgo de brotes del virus mancha blanca

\begin{tabular}{|c|c|c|c|}
\hline Año & $\begin{array}{c}\text { Área total piscinas } \\
(\mathbf{H a})\end{array}$ & $\begin{array}{c}\text { Área vulnerable }\left(\mathbf{T} \leq \mathbf{2 7}^{\circ} \mathbf{C}\right) \\
(\mathbf{H a})\end{array}$ & $\begin{array}{c}\text { Porcentaje } \\
\mathbf{\%}\end{array}$ \\
\hline 2016 & 12569,76 & 16,20 & $0,13 \%$ \\
\hline 2017 & 12736,80 & 1644,48 & $12,91 \%$ \\
\hline
\end{tabular}

En base a los resultados obtenidos, para el año 2016, un 0,13\% del área total de piscinas camaroneras presentan riesgo de brote del virus de la mancha blanca, un porcentaje muy pequeño respecto al área total de piscinas identificadas en ese año, mientras que, para el año 2017 un $12,91 \%$ del área total de piscinas camaroneras son zonas vulnerables para este virus, un porcentaje mucho más representativo en comparación con el área total de piscinas en ese año. Estas diferencias podrían deberse también a factores climatológicos de la zona de estudio, donde según Palacios y Rosero (2013), los meses de diciembre-mayo se considera como periodo lluvioso, mientras que junio-octubre un periodo seco, según el mes de la toma de captura de la imagen, para el año 2016 (mayo) le correspondería un periodo lluvioso, y para el año 2017 (octubre) un periodo seco. Se optó por elegir imágenes de diferentes periodos (seco/lluvioso) para observar su influencia en el riesgo de brote del virus. Cabe mencionar que, en el año 2016 de las 16,20 ha de piscinas con riesgo al virus, 11,88 ha mantuvieron esta anomalía para el año 2017.

\section{CONCLUSIONES}

La Isla Puná concentra un gran número de empresas camaroneras a nivel nacional, para el año 2016 presenta 16,20 ha de piscinas camaroneras con riesgo a brotes del virus de la mancha blanca, mientras que para el año 2017 aumenta a 1644,48 ha, estas cifras demuestran la falta de un mayor control por parte de las autoridades competentes en el proceso de producción camaronera para el año 2017, que además podría verse influenciado por las altas temperaturas en el ambiente que presenta el periodo seco.

Los datos de emisividad global del sensor ASTER, representan una alternativa a los métodos que calculan la emisividad en base al manejo de las bandas del mismo sensor, lo cual permite el manejo de datos de emisividad más precisos para el cálculo de temperatura superficial.

La metodología expuesta para el cálculo de temperatura en piscinas camaroneras mediante teledetección, supondría un aporte importante en la tecnología y métodos de cuidado para disminuir el riesgo de que la especie Litopenaeus vannamei contraiga el virus de la mancha blanca, puesto que con la identificación de posibles zonas vulnerables a este virus, se podría ejercer un mayor control en las piscinas y mejorar la calidad de producción en el sector camaronero. 


\section{REFERENCIAS}

Aguilar, H., Mora, R., and Vargas, C. (2014). METODOLOGÍA PARA LA CORRECCIÓN ATMOSFÉRICA DE IMÁGENES ASTER, RAPIDEYE, SPOT 2 Y LANDSAT 8 CON EL MÓDULO FLAASH DEL SOFTWARE ENVI. Revista Geográfica de América Central(53), 39-59. Obtenido de https://doi.org/10.15359/rgac.2-53.2

Armas, W., and Izquierdo, L. (2010). Caracterización y propuesta técnica de la acuicultura en la parroquia rural de Puná del cantón Guayaquil. Tesis de Grado, Escuela Superior Politécnica del Litoral, Facultad de Ingeniería Marítima y Ciencias del Mar, Guayaquil. Obtenido de http://suia.ambiente.gob.ec/documents/783967/890048/Caracterizaci\%C3\%B3n+y+Prop uesta+T\%C3\%A9cnica+De+La+Acuicultura+En+La+Parroquia+Rural+Pun\%C3\%A1\% 20Del+Cant\%C3\%B3n+Guayaquil.pdf/192cd01a-ce49-4088-8b4a2daf768a0037;jsessionid=2TCMggtUsNKBDWL3ubRghI0m

Becker, F., and Li, Z.-L. (1990). Towards a local split window method over land surfaces. International Journal of Remote Sensing, 11(3), 369-393. Obtenido de http://dx.doi.org/10.1080/01431169008955028 PLEASE

Blake, S. (2004). Contribución al estudio de los mecanismos celulares empleados por el camarón Litopenaeus vannamei para eliminar el virus del síndrome de la mancha blanca (wssv). Escuela Superior Politécnica del Litoral (ESPOL), Facultad de Ingeniería Marítima y Ciencias del Mar, Guayaquil. Obtenido de http://www.cenaim.espol.edu.ec/sites/cenaim.espol.edu.ec/files/04_blakesara.pdf

Briggs, M., Funge-Smith, S., Subasinghe, R., and Phillips, M. (2005). Introducciones y movimiento de dos especies de camarones peneidos en Asia y el Pacífico. FAO Documento Técnico de Pesca 476, Organización de las Naciones Unidas para la Alimentación (FAO), Roma. Obtenido de http://www.fao.org/3/a0086s/A0086S00.htm\#TOC

Chuvieco, E. (1992). Teledetección S.I.G. y Cambio Global. Geographicalia(29), 33-54. Obtenido https://www.researchgate.net/publication/28315399_Teledeteccion_SIG_y_Cambio_Glo bal

Cuéllar-Anjel, J. (Agosto de 2013). Enfermedad de las manchas blancas. The Center for Food Security Public Health (CFSPH), IOWA State University. Obtenido de http://www.cfsph.iastate.edu/Factsheets/es/white-spot-disease-es.pdf

Dražen, S. (2017). Calibration and Validation of Thermal Infrared Remote Sensing Sensors and Land/Sea Surface Temperature algorithms over the Iberian Peninsula. Tesis doctoral en Teledetección, Universidad de Valencia, Departamento de Física de la Tierra y Termodinámica, Valencia. Obtenido de https://core.ac.uk/download/pdf/84750704.pdf

Galve, J. (2014). Generación y validación de algoritmos para la obtención de la temperatura de la superficie terrestre utilizando técnicas de Teledetección en el infrarrojo térmico. Tesis pregrado, Universitat de València, España. Obtenido de https://dialnet.unirioja.es/servlet/dctes?codigo $=90621$

Jiménez-Muñoz, J., and Sobrino, J. (2008). Split-Window Coefficients for Land Surface Temperature Retrieval From Low-Resolution Thermal Infrared Sensors. IEEE Geoscience and Remote Sensing Letters, 5(4), 806-809. Obtenido de https://ieeexplore.ieee.org/document/4656465

Jiménez-Muñoz, J., Sobrino, J., Skokovic, D., Mattar, C., and Cristóbal, J. (2014). Land Surface Temperature Retrieval Methods From Landsat-8 Thermal Infrared Sensor Data. IEEE 
Geoscience and Remote Sensing Letters, 11(10), 1840-1843. Obtenido de https://ieeexplore.ieee.org/document/6784508

Li, S., and Geng-Ming, J. (2018). Land Surface Temperature Retrieval From Landsat-8 Data With the Generalized Split-Window Algorithm. IEEE Access, 6, 18149 - 18162. Obtenido de https://ieeexplore.ieee.org/abstract/document/8323370

NASA. (2014). ASTER Overview. Obtenido de https://lpdaac.usgs.gov/dataset_discovery/aster?fbclid=IwAR1HAAjxX7Dm1xmcx_opcQ8thDR-JC4Cte5aG4mHJOBQCnhZ6RjMHd7Xbs

NASA. (2018). Aster Mission. Obtenido de https://asterweb.jpl.nasa.gov/mission.asp?fbclid=IwAR0B0A6t0Dc6m0EEBaiv84eZH8B y06B_DXgG-jobu63_uoPdcuXpjsN1I-o

Palacios, J., and Rosero, D. (2013). Análisis de las condiciones climáticas registradas en el Ecuádor continental en el año 2013 y su impacto en el sector agrícola. Instituto Nacional de Hidrología y Meteorología (INHAMI), Quito.

Santana, N. (2015). Factores de auge, crisis y recuperación del sector camaronero ecuatoriano en el período 1994-2014. Tesis maestría, Universidad de Guayaquil, Facultad de Ciencias Económicas, Guayaquil. Obtenido de http://repositorio.ug.edu.ec/bitstream/redug/7158/1/PROYECTO\%20FINAL\%20DE\%20 TESIS\%20NARCISA\%20SANTANA\%20NAVARRO.pdf

Sarría, A. (2018). Cálculo de temperatura de superficie a partir de imágenes Landsat, NOAA y Sentinel-3. Universidad Politécnica de Valencia, Escuela Técnica Superior de Ingeniería Geodésica, Cartográfica y Topográfica , Valencia. Obtenido de https://riunet.upv.es/bitstream/handle/10251/103166/Fern\%C3\%A1ndez\%20$\%$ 20CALCULO $\% 20 \mathrm{DE} \%$ 20TEMPERATURA $\% 20 \mathrm{DE} \% 20$ SUPERFICIE\%20A\%20PA RTIR\%20DE\%20IM\%C3\%81GENES\%20NOAA\%2c\%20LANDSAT\%20Y\%20SENTI NEL-3.pdf?sequence $=1$ and isAllowed $=\mathrm{y}$

Sarricolea, P., and Vide, J. (2014). El estudio de la Isla de Calor Urbana de Superficie del Área Metropolitana de Santiago de Chile con imágenes Terra-MODIS y Análisis de Componentes Principales. Revista de geografía Norte Grande(57), 123-141. Obtenido de http://dx.doi.org/10.4067/S0718-34022014000100009

Shahid, M. (2014). Land Surface Temperature Retrival of Landsat-8 Data Using Split Window Algorithm- A Case Study of Ranchi District. International Journal of Engineering Development and Research (IJEDR), 2(4), 3840-3849. Obtenido de http://www.ijedr.org/papers/IJEDR1404073.pdf

Sobrino, J., Li, Z.-L., Stoll, M., and Becker, F. (1996). Multi-channel and multi-angle algorithms for estimating sea and land surface temperature with ATSR data. International Journal of Remote Sensing, 17(11), 2089-2114. Obtenido de http://dx.doi.org/10.1080/01431169608948760

Sobrino, J., Raissouni, N., Kerr, Y., Olioso, A., López-García, M., Belaid, A., . . Dempere, L. (2000). Teledetección. (J. A. Sobrino, Ed.) Valencia, España: Servicio de Publicaciones.

Vélez, A. (2015). Causas de la recuperación del sector camaronero en el Ecuador: 2014. Tesis maestría, Universidad de Guayaquil, Facultad de Ciencias Económicas, Guayaquil. 